\title{
Psychological Determinants of the Intention to Use the Bus in Ho Chi Minh City
}

\author{
Satoshi Fujii and Hong Tan Van \\ Tokyo Institute of Technology
}

\begin{abstract}
This study explores the behavioral intention to use the bus while considering the perceived quality of bus service, problem awareness, and moral obligation of people in Ho Chi Minh City (HCMC), Vietnam. The purpose is to test the feasibility of developing mobility management measures persuading motorcycle users to use the bus more, and if so, how. Principal components analysis on a set of psychological factors related to various aspects of bus use yielded four factors: moral concerns, negative expression, quality perception, and social status. The regression of the intention on these four factors revealed that determinants of intention to use the bus in HCMC are moral concerns and the perception of quality. Based on the psychological relationships, mobility management measures can be applied in persuading people to change their behavior toward using the bus.
\end{abstract}

\section{Introduction}

Public transportation provides a very important travel mode in human society, and for decades has provided basic mobility for the vast majority of travelers. Studies have shown that provision of proper public transportation would mitigate traffic congestion, reduce $\mathrm{CO}_{2}$ emissions, and improve efficiency of energy consumption, as well as make the society more equitable in terms of mobility 
(Shapiro et al. 2002, American Public Transportation Association 2007). All of these outcomes are the main constituent factors of sustainable development (Victoria Transport Institute 2008). Therefore, a strategy to develop a well-performing public transportation service should have a special place in the overall strategy of transportation planning.

Even so, downward trends in the use of urban public transportation now exist not only in developed countries (Hensher 1998) but also in many developing countries (Mohamad and Kiggundu 2007). In developing countries, the bus is typically the backbone of public transportation (Tiwari 1999, Susilo et al. 2007) and the primary means of transportation for many low-income people (Sohaila et al. 2004). However, large economic growth followed by rapid motorization has led to the increase in privately-owned transportation and a consequent remarkable drop in the patronage of public transportation (Morichi 2005). This imbalance between transportation modes can be seen in many cities. For example, in Ho Chi Minh City (HCMC), Vietnam, only 5 percent of trips occur by bus, whereas almost all the rest are by motorcycle (HCMC Department of Transport 2007a). The solution to such an extreme situation must be a combination of not only "hard" measures such as improving the quality of the bus service but also "soft" measures such as mobility management. Mobility management has been successful in Japan, which uses the Travel Feedback Program for travel behavior change (Fujii and Taniguchi 2006), and in the United Kingdom, which employs Travel Plans (UK Department of Transport 2004). In fact, after investigating the psychological structure of people in HCMC, Van and Fujii (2007) concluded that mobility management has the potential for inducing behavioral change in that city. The aim of this paper is to investigate the effect of psychological factors concerning bus use on motorcycle users' behavioral intention of using the bus in HCMC. This could be considered an important step toward developing mobility management measures to influence the behavior of motorcycle users in HCMC toward bus use.

Quality of service is an important factor in the widespread use of public transportation (Paulley et al. 2006). In addition, transportation quality is acknowledged to consist of two parts: the objective aspect, such as performance measures, and the psychological aspect or service measures, such as how customers perceive the service (Kittelson and Associates, Inc. et al. 2003). If HCMC's bus service is examined objectively, statistics (HCMC Department of Transport 2007b) show that the bus, which is the only public transportation mode in HCMC, has seen heavy investment since 2002. Buses serve 24 corridors and are spreading to many smaller 
roadways. In the inner districts, the areas where the questionnaires for this study were distributed, a bus stop can be found within 15-20 minutes' walking distance of most residences. This implies that few cases exist in which finding a nearby bus stop poses a problem. Bus fares vary according to route and could make transfers more costly and less convenient. Although the buses are generally equipped with air conditioning, it is observed that few of these actually operate while the buses are running. Moreover, due to the imbalance between the transportation modes, the movement of buses is greatly impeded by motorcycles during peak hours.

From the psychological perspective, Van and Fujii (2007) found that the bus service in HCMC was evaluated as neutral in all three aspects of symbolic, instrumental, and social orderliness when investigating the images of bus and other travel modes in HCMC. Since the purpose of this paper is to formulate mobility management strategies to influence HCMC motorcycle users to start using the bus, having sufficient knowledge about the relationship between the behavioral intention to use the bus and psychological factors related to bus service is critically important. Among such factors, the perceived quality of bus service could be considered key since it would reflect whether the service is attractive to prospective customers. In fact, research on similar issues regarding the quality of transit service perceived by bus users has confirmed this assumption. For example, Eboli and Mazzulla (2007) found that perceived quality attributes of bus service had an impact on customer satisfaction, and Joewono and Kubota (2007) also found a significant relationship between overall satisfaction and loyalty to use the transit service in the future. Jen and $\mathrm{Hu}$ (2003) concluded that passengers' repurchase intentions were determined by their perceived value of the bus service. In addition to the perceived quality of service, research on public transportation by Friman et al. (2001) and Friman and Gärling (2001) found that the frequency of negative critical incidents had significant impacts on user satisfaction with the public transportation service. Furthermore, other studies (Grob 1995, Stern 2000, Norlund and Garvill 2003, Fuji 2006) also demonstrated that problem awareness and moral obligation were important antecedents for pro-environmental behavioral intention and behavior. A review of these studies shows that the perceived quality of bus service, negative critical incidents, problem awareness, and moral obligation factors could be determinants of behavioral intention. Given this background, this study hypothesized that for motorcycle users in HCMC, perceived quality of bus service, problem awareness, and moral obligation would have positive effects on their intentions to use the bus, while the negative critical incidents would have a negative effect on such intentions. 
Traffic congestion in HCMC due to the excessive use of motorcycles has reached an alarming level. Moreover, car ownership in the city has been increasing rapidly in the last three years. Therefore, solutions to change the behavior of motorcycle users using psychological approaches such as mobility management are especially important for HCMC. With such a motivation, empirical analysis of motorcycle users' intention to use the bus by considering the effects of psychological factors is presented.

\section{Method}

\section{Sample}

The data of this research were based on the second part of a two-part questionnaire. In the first part, respondents were asked to recall two most recent trips by motorcycle (short and long) and answer questions about those trips. Respondents were, therefore, presumed to be motorcycle users.

A mail-back survey was conducted in late August 2007 in HCMC. Questionnaires were mailed to 1,000 households randomly chosen from the city's phone list and evenly distributed across 18 districts of the city. Each target household received one survey questionnaire form along with one stamped envelope for return and an incentive pen valued at VND 4000 (approximately US \$0.25). A total of 285 responses was returned, a response rate of 28.5 percent. Since three were excluded due to missing data, this study was based on a sample of 282 motorcycle users whose mean age was 40.9 years $(S D=12.2$ ). Compared to the average age of the driving-age population (from 16 to 70 years), which is around 35 (Statistical Office in Ho Chi Minh 2005, HCMC Department of Transport 2007b), the average age of this sample was a bit high. Of these respondents, 49.6 percent were male, 24.8 percent owned bicycles, 87.2 percent owned motorcycles, and 1.8 percent owned cars. Socio-demographic statistics of HCMC's population at driving ages indicated that, at the time of implementation of the survey, the motorcycle ownership rate was estimated to be around 74.9 percent, while for car it was around 3.3 percent. Also, according to census data, 48.5 percent of the driving-age population was male. Considering the differences between motorcycle users and people at driving ages, it is therefore possible to speculate that this sample could reflect well the characteristics of motorcycle users of the city as a whole, and thus could be considered to be representative of the HCMC population. 


\section{Measurement}

To increase the response rate, which was predicted to be low due to possible lack of cooperation by respondents, the questionnaire was designed to be as concise as possible. For this study, the most relevant questions were selected to obtain (i) attitudinal factors toward bus service, (ii) frequency of negative critical incidents, (iii) problem awareness, (iv) moral obligation, and ( $v$ ) behavioral intention of using the bus.

Attitudinal factors toward bus service included questions about the perceived quality of bus service and about other aspects of using the bus (see Table 1). Given the ambiguity in the definition of attributes that comprise public transportation performance (Thompson and Schofield 2007), attributes related to the quality of bus service and the attitudes toward other aspects of bus use were empirically selected to be those most representative of the bus service characteristics in $\mathrm{HCMC}$ based on the literature review. Each item was assessed on a five-point scale ranging from -2 to 2 .

\section{Table 1. Attitudinal Factors Toward Bus Service and Negative Critical Incidents}

\begin{tabular}{|l|l|}
\hline \multicolumn{1}{|c|}{ Item } & Question (scale) \\
\hline $\begin{array}{l}\text { Behavioral } \\
\text { intention }\end{array}$ & $\begin{array}{l}\text { Do you intend to use the bus instead of your motorcycle in the future for most of your trips? } \\
\text { (No, I don't-Yes, I do) }\end{array}$ \\
\hline+ +Perceived Quality of Bus Service \\
\hline Comfort & How comfortable do you think a bus ride is in HCMC? (Uncomfortable-Comfortable) \\
\hline Convenience & How convenient do you think the bus is for your trips? (Inconvenient-Convenient) \\
\hline Speed & How fast do you think bus service is in HCMC? (Slow-Fast) \\
\hline Punctuality & How punctual do you think the arrival of buses is in HCMC? (Irregular-Punctual) \\
\hline Security & What do you think about the onboard security when riding on a bus? (Unsafe-Safe) \\
\hline Courtesy & How would you rate the courtesy of the bus staff? (Rude-Courteous) \\
\hline Time_cost & Do you think it would require much time and effort for you to use the bus? (Not at all-Strongly yes) \\
\hline Money_cost & Do you think it would cost a lot for you to use the bus? (Not at all-Strongly yes) \\
\hline Overall_Q & What do you think or know about the overall quality of bus service? (Bad-Good) \\
\hline+ Frequency of Negative Critical Incidents \\
\hline Incident 1 & Have you ever experienced overcrowding onboard a bus? \\
\hline Incident 2 & Have you ever experienced the driver completely forgetting to stop to let you on or off? \\
\hline Incident 3 & Have you ever experienced you or someone being pocketed on a bus? \\
\hline Incident 4 & Have you ever had trouble with rude passengers on a bus? \\
\hline+ Attitudes Toward Other Aspects of Using the Bus \\
\hline Poorness & Do you think that you would be considered poor if you were to use the bus? (Not at all-Strongly yes) \\
\hline Interaction & Do you dislike traveling with those you don't know well? (Not at all-Strongly yes) \\
\hline P_Aware1 & Do you think that using bus would help reduce air pollution for HCMC? (Not at all-Strongly yes) \\
\hline P_Aware2 & Do you think that using bus would help mitigate traffic congestion for HCMC? (Not at all-Strongly yes) \\
\hline MO1 & Do you think you should be voluntary to use bus for better traffic in the city? (Not at all-Strongly yes) \\
\hline MO2 & Do you think that residents in HCMC should use bus more? (Not at all-Strongly yes) \\
\hline
\end{tabular}

Based on the work of Friman et al. (1998), four incidents were selected that were most typical of HCMC bus service (see Table 1). Respondents were asked about the frequency of negative incidents experienced in the past regarding bus use. 
Responses were rated on a simple five-point scale ranging from - 2 to 2 (Never to Regularly) to make the questionnaire easier to answer, especially for people in a developing city who are likely new to questionnaire surveys.

It can be observed from Table 2 that the dependent variable seems to be well distributed around 0. A Kolmogorov-Smirnov test indicated that the dependent variable was normally distributed with a confident level of $95 \%$. The mean intention to use the bus in the sample was 0.91 ( $S D=0.96$ ), implying that the sample did not have a strong intention to use the bus in the future.

\section{Table 2. Distribution of the Dependent Variable}

\begin{tabular}{|l|c|c|c|c|c|}
\hline \multirow{2}{*}{ Variable } & \multicolumn{5}{|c|}{ Distribution of scores (\%) } \\
\cline { 2 - 6 } & -2 & -1 & 0 & 1 & 2 \\
\hline Intention to use the bus & 11.0 & 14.9 & 49.2 & 21.6 & 3.2 \\
\hline
\end{tabular}

\section{Results}

\section{Principal Components Analysis}

A principal components analysis (PCA) using varimax rotation was performed on all perceptions except behavioral intention to determine principal components that could summarize the judgments about various aspects of bus use. The result of the PCA identified four main factors, accounting for 48.3 percent of the total variance. Table 3 presents only perceptions having factor loading $|\geq 0.4|$, which is considered large and meaningful for explaining the factors (Stevens 1986).

Factor 1 accounted for 21.2 percent of the total variance. This factor expresses "moral concerns" regarding bus use because two perceptions of problem awareness and two perceptions of moral obligation, both individual and societal scales, had high loadings on this factor. Factor 2 made up 10.6 percent of the total variance. Perceptions scoring high on this factor were the frequency of negative incidents and the discourtesy of bus staff; this factor was therefore referred as a negative impression. Factor 3 accounted for 9.4 percent of the variance and describes the quality of service, since all of the perceptions having high loadings on this factor were attributes of the perception of quality of bus service. Note that the perception about the overall quality of service simultaneously had a high negative factor loading on Factor 2, implying that the poor quality of service would also cause negative impression to people. Factor 4 accounted for 7.1 percent of the variance. The perceptions regarding social interaction and being poor loaded 


\section{Table 3. Rotated Factor Loadings of Perceptions about Bus Service}

\begin{tabular}{|l|c|c|c|c|}
\hline & \multicolumn{4}{|c}{ Component } \\
\cline { 2 - 4 } Perception & $\begin{array}{c}\text { Moral } \\
\text { concerns }\end{array}$ & $\begin{array}{c}\text { Negative } \\
\text { impression }\end{array}$ & $\begin{array}{c}\text { Quality } \\
\text { perception }\end{array}$ & $\begin{array}{c}\text { Social } \\
\text { status }\end{array}$ \\
\hline P_Aware2 & 0.798 & & & \\
\hline P_Aware1 & 0.780 & & & \\
\hline MO2 & 0.746 & & & \\
\hline MO1 & 0.710 & & & \\
\hline Security & & & & \\
\hline Incident 4 & & 0.727 & & \\
\hline Incident 3 & & 0.631 & & \\
\hline Incident 2 & & 0.629 & & \\
\hline Incident 1 & & 0.576 & & \\
\hline Courtesy & & -0.476 & & \\
\hline Convenience & & & & \\
\hline Time_cost & & & -0.672 & \\
\hline Speed & & & 0.636 & \\
\hline Comfort & & & 0.557 & \\
\hline Money_cost & & & -0.531 & \\
\hline Overall_Q & & -0.439 & 0.512 & \\
\hline Punctuality & & & 0.428 & \\
\hline Poorness & & & & \\
\hline Interaction & & & & \\
\hline Variance & & & & \\
\hline explanation (\%) & 21.2 & 10.6 & & \\
\hline
\end{tabular}

Note: Only factor loadings $|\geq 0.4|$ are noted.

high on this factor, so Factor 4 can be interpreted as the social status of the bus. Based on the results of the PCA, four new variables (factor scores) were calculated using regression method. Note that these new variables are independent of each other, so using this technique avoids any drawbacks such as multicollinearity in regression analysis.

\section{Regression Analysis}

Using the psychological variables generated by the PCA, an ordered logistic regression analysis was conducted with behavioral intention to use the bus as the dependent variable. This analytic approach is appropriate in explaining the possible non-linearity and the ordinal property of the dependent variable. Regarding explanatory factors, in addition to hypothesized psychological variables, Age, Gen- 
$\operatorname{der}($ male $=1)$ and Bicycle ownership (owning $=1$ ) were also included to test the effect of socioeconomic factors. The estimation result is presented in Table 4.

\section{Table 4. Estimation Results of Ordered Logistic Regression of Behavioral Intention to Use the Bus}

\begin{tabular}{|c|c|c|c|}
\hline & $\beta$ & S.E. & $p$ \\
\hline \multicolumn{4}{|l|}{ + Threshold parameters } \\
\hline$\theta 1$ & -2.02 & 0.48 & $<0.001$ \\
\hline$\theta 2$ & -0.56 & 0.45 & 0.209 \\
\hline$\underline{\theta 3}$ & 2.82 & 0.48 & $<0.001$ \\
\hline$\theta 4$ & 5.8 & 0.62 & $<0.001$ \\
\hline \multicolumn{4}{|l|}{ + Independent variables } \\
\hline Moral concerns ${ }^{* * *}$ & 1.50 & 0.15 & $<0.001$ \\
\hline Negative impression & -0.13 & 0.12 & 0.272 \\
\hline Quality perception*** & 0.79 & 0.13 & $<0.001$ \\
\hline Social status & -0.07 & 0.12 & 0.548 \\
\hline $\mathrm{Age}^{* * *}$ & 0.04 & 0.01 & $<0.001$ \\
\hline Gender, dummy* & -0.64 & 0.25 & 0.010 \\
\hline Bicycle ownership, dummy & -0.12 & 0.28 & 0.67 \\
\hline \multicolumn{4}{|c|}{ Log Likelihood. $\chi^{2}$, pseudo $\mathrm{R}^{2}: 573.94,168.37,0.227$} \\
\hline
\end{tabular}

As seen in Table 4, the coefficient of quality perception was significant at $p<0.001$, supporting one part of the hypothesis that the intention to use the bus would increase with perceived quality of bus service. Additionally, the hypothesis regarding problem awareness and moral obligation also held true in this sample. Specifically, the factor of moral concerns was found to be significant in the behavioral intention to use the bus. This finding means that being aware of the contribution of bus use to mitigate air pollution and traffic congestion as well as understanding that one should act in the collective interest would make motorcycle users more likely to use the bus. In addition, the coefficients show that the influence of the moral concerns factor was much stronger than that of quality perception and was the strongest variable in affecting behavioral intention in this model. These results imply that mobility management measures to enhance people's awareness about 
the benefits of bus use in improving the current traffic and environment situation in HCMC would be effective in persuading people to use the bus.

However, as Table 4 shows, no significant effect of negative impression on intention to use the bus was detected. Since the factor of negative impression in this study was primarily based on the frequency of negative incidents, the result of this study using the sample of motorcycle users in HCMC did not conform to the findings of Friman et al. (2001) or Friman and Gärling (2001). Social status also did not significantly influence the behavioral intention by implying that perceptions such as poorness or social interaction related to bus use would not lessen people's intentions to use the bus.

In addition, Table 4 also shows that Age was positively significant in the behavioral intention to use the bus. That is, older respondents had more intention to use the bus than the younger respondents $(t=2.84)$. Meanwhile, Gender had negative and significant effects on behavioral intention $(t=-2.59)$. This means that females were more likely to intend using the bus than males. Unexpectedly, Bicycle ownership did not have any effect on behavioral intention to use the bus.

\section{Discussion}

This study examined the effect of various psychological factors for motorcycle users on their intentions to use the bus in HCMC. Judgments of respondents about various aspects of bus service were summarized by the PCA into the four factors of moral concerns, negative impression, quality perception, and social status. Ordered logit model results of behavioral intention with four psychological factors as explanatory variables showed that moral concerns and quality perception were determinants of behavioral intention to use the bus. These findings imply that mobility management measures would be applicable to changing the behavior of motorcycle users toward bus use.

As mentioned in the introduction, several studies have demonstrated the causal relationship between perceived quality of bus service and customer satisfaction (e.g., Eboli and Mazzulla 2007, Joewono and Kubota 2007). In view of that finding, in this study, we chose to hypothesize about the possible effect of the perceived quality of bus service on the behavioral intention of non-bus users. The result indicates that the hypothesis about the positive influence of quality perception of the bus service on behavioral intention was confirmed in HCMC, where the target of the survey was the majority of motorcycle users. Thus, efforts to make 
bus service in HCMC more attractive to motorcycle users would consequently increase patronage for the bus. As a previous study found, private transportation users tend to have "negative" beliefs about public transportation (Fujii et al. 2001). If motorcycle users in HCMC had negative perceptions about the quality of bus service as implied by the data, precise information on the "objective" perspective of quality of bus service may improve its "perceived" quality and may strengthen behavioral intention to use the bus. Further studies are necessary to confirm this theoretical potential of providing objective information.

The result of the regression analysis supported another hypothesized relationship between problem awareness, moral obligation, and behavioral intention. That is, the factor of moral concerns was found to be the largest coefficient significantly influencing the intention to use the bus. This result is in accordance with the results reported by Nordlund and Garvill (2003) and Fujii (2006) stating that problem awareness and moral obligation were important antecedents for pro-environmental behavioral intentions and behaviors. In a similar vein, Gärling et al. (2003) found that problem awareness for the biosphere and for the society at large has a larger impact than for oneself. This result implies that change from motorcycle use to bus use might be regarded as a cooperative or socially-desirable behavior rather than an egocentric behavior that tries to maximize one's self-interest.

For HCMC, the significance of the factor of moral concerns indicates that a communicative mobility management measure that tries to activate moral obligation regarding implementation of socially-desirable travel behavior could be expected to have potential for convincing people to use the bus in HCMC. Accordingly, increasing the behavioral intention to use the bus in HCMC can be achieved by enhancing public awareness of the benefits of bus use toward improving the environment and mobility for society. Increasing behavioral intention can also be achieved by making people feel "morally responsible" to cooperate in solving the current traffic situation. This would be a very important mission, not only for transportation planners, but for the public as well.

Last, the ordered logistic regression model in this study still did not have high goodness of fit, as shown by the pseudo R square. This implies that other important determinants are involved in the behavioral intention to use the bus. The factor of negative critical incidents as suggested by Friman et al. (1998), as well as other socioeconomic factors such as vehicle ownership, were examined, but the results were not as expected. Perhaps the inclusion of other psychological factors such as perceived behavioral control or social norms as suggested in the Ajzen's 
"Theory of Planned Behavior" (1991) could increase the variance explanation as well as improve our knowledge about the psychological characteristics of using the bus in HCMC. Such deficiencies in this study should be explored in follow-up research.

\section{References}

Ajzen, I. 1991. The theory of planned behavior. Organizational Behavior and Human Decision Processes 50(2): 179-211.

American Public Transportation Association. 2007. Public transportation: Benefits for the 21st century. Available at http://www.apta.com/research/info/online/ documents/twenty_first_century.pdf

Eboli, L., and G. Mazzulla. 2007. Service quality attributes affecting customer satisfaction for bus transit. Journal of Public Transportation 10(3): 21-34.

Friman, M., and T. Gärling. 2001. Frequency of negative critical incidents and satisfaction with public transport services. II. Journal of Retailing and Consumer Services 8: 105-114.

Friman, M., B. Edvardsson, and T. Gärling. 1998. Perceived service quality attributes in public transport: Inferences from complaints and negative critical incidents. Journal of Public Transportation 2(1): 67-88.

Friman, M., B. Edvardsson, and T. Gärling. 2001. Frequency of negative critical incidents and satisfaction with public transport services. I. Journal of Retailing and Consumer Services 8: 95-104.

Fujii, S. 2006. Environmental concern, attitude toward frugality, and ease of behavior as determinants of pro-environmental behavior intentions. Journal of Environmental Psychology 26: 262-268.

Fujii, S., and A. Taniguchi. 2006. Determinants of the effectiveness of travel feedback programs: A review of communicative mobility management measures for changing travel behavior in Japan. Transport Policy 13(5): 339-348.

Fujii, S., T. Gärling, and R. Kitamura. 2001. Changes in drivers' perceptions and use of public transport during a freeway closure: effects of temporary structural change on cooperation in a real-life social dilemma. Environment and Behavior 33(6): 796-808. 
Gärling, T., S. Fujii, A. Gärling, and C. Jakobsson. 2003. Moderating effects of social value orientation on determinants of pro-environmental behavior intention. Journal of Environmental Psychology, 23(1): 1-9.

Grob, A. 1995. A structural model of environmental attitudes and behavior. Journal of Environmental Psychology 15: 209-220.

HCMC Department of Transport. 2007a. Plan for mitigation of traffic congestion and traffic accidents in Ho Chi Minh City from 2007 to 2010. Document submitted to Ho Chi Minh City People Committee in May 2007 (in Vietnamese).

HCMC Department of Transport. 2007b. Proposal of planning transportation for Ho Chi Minh City from 2007 to 2020. Document submitted to Ho Chi Minh City People's Council in November 2007 (in Vietnamese).

Hensher, D.A. 1998. The imbalance between car and public transport use in urban Australia: Why does it exist? Transport Policy 5: 193-204.

Jen, W., and K.C. Hu. 2003. Application of perceived value model to identify factors affecting passengers' repurchase intentions on city bus: A case of the Taipei Metropolitan Area. Transportation 30: 307-327.

Joewono, T.B., and H. Kubota. 2007. User perception of private paratransit operation in Indonesia. Journal of Public Transportation 10(4): 99-118.

Kittelson and Associates, Inc., KFH Group, Parsons Brinckerhoff Quade and Douglass, Inc., and K.H. Zaworski. 2003. TCRP Report 100: Transit capacity and quality of service manual, 2 nd edition. Transportation Research Board. Available at http://onlinepubs.trb.org/onlinepubs/tcrp/tcrp100/part\%200.pdf

Mohamad, J., and A.T. Kiggundu. 2007. The rise of private car in Kuala Lumpur, Malaysia: Assessing the policy options. IATSS Research 31(1): 69-77.

Morichi, S. 2005. Long-term strategy for transport system in Asian megacities. Journal of the Eastern Asia Society for Transportation Studies 6: 1-22.

Nordlund, A.M., and J. Garvill. 2003. Effects of values, problem awareness, and personal norm on willingness to reduce personal car use. Journal of Environmental Psychology 23: 339-347.

Paulley, N., R. Balcombe, R. Mackett, H. Titheridge, J. Preston, M. Wardman, J. Shires, and P. White. 2006. The demand for public transport: The effects of 
fares, quality of service, income and car ownership. Transport Policy 13(4): 295-306.

Shapiro, R.J., K.A. Hassett, and F.S. Arnold. 2002. Conserving energy and preserving the environment: The role of public transportation. Report commissioned by the American Public Transportation Association. Available at http://www. apta.com/research/info/online/documents/shapiro.pdf

Sohaila, M., D.A.C. Maunderb, and D.W.J. Miles. 2004. Managing public transport in developing countries: Stakeholder perspectives in Dar es Salaam and Faisalabad. International Journal of Transport Management 2(3-4): 149-160.

Statistical Office in Ho Chi Minh. 2005. Mid-term population investigation year 2004 (in Vietnamese).

Stern, P.C. 2000. Toward a coherent theory of environmentally significant behavior. Journal of Social Issues 56: 407-424.

Stevens, J. 1986. Applied Multivariate Statistics for the Social Sciences. Hillsdale, NJ: Lawrence Erlbaum Associates.

Susilo, Y.O., T.B. Joewono, W. Santosa, and D. Parikesit. 2007. A reflection of motorization and public transport in Jakarta Metropolitan Area. IATSS Research 31(1): 59-68.

Thompson, K., and P. Schofield. 2007. An investigation of the relationship between public transport performance and destination satisfaction. Journal of Transport Geography 15(2): 136-144.

Tiwari, G. 1999. Towards a sustainable urban transport system: planning for nonmotorized vehicles in cities. Transport and Communications Bulletin for Asia and the Pacific 68: 49-66.

UK Department of Transport. 2004. Smarter Choices: Changing the Way We Travel. London, UK.

Van, H.T., and S. Fujii. 2007. Psychological determinants of behavioral intention to use travel modes in Ho Chi Minh City. Proceedings of the Eastern Asia Society for Transportation Studies 6: CD-ROM.

Victoria Transport Institute. 2008. Sustainable transportation and TDM, Planning that balances economic, social and ecological objectives. In Online TDM Encyclopedia. Available at http://www.vtpi.org/tdm/tdm67.htm 


\section{About the Authors}

SAтоsH FuJII (fujii@plan.cv.titech.ac.jp) is a professor in the Department of Civil Engineering at the Tokyo Institute of Technology, Japan. His current research objective is to apply social psychology to transportation policy making, and his research interests include travel behavior analyses, behavioral decision making, personal judgment and decision making in social dilemmas, and attitudes toward public policies.

Hong TAN VAN (vhtan@plan.cv.titech.ac.jp) is a PhD student in the Department of Civil Engineering at the Tokyo Institute of Technology, Japan. He holds a master's degree in transportation engineering from the Tokyo Institute of Technology. His research interests are transportation demand management, behavior change, and public transportation. 